\title{
Cooperativismo: evolução histórica e contribuições para os processos organizativos de cooperativas de agricultores familiares praticantes da agroecologia
}

Denise Medianeira Mariotti Fernandes ${ }^{1}$

Erica Karnopp ${ }^{2}$

\section{Resumo}

O presente artigo tem por objetivo descrever processos organizativos de cooperação desenvolvidos em cooperativas de agricultores familiares que adotam e/ ou incentivam práticas agroecológicas, a partir da organização de ações coletivas presentes em duas realidades distintas: a primeira, da Cooperativa Cooesperança, no município de Santa Maria, estado do Rio Grande do Sul, Brasil; e a segunda, da Cooperativa La Choza, no município de General Rodriguez, província de Buenos Aires, Argentina. Para atingi-lo, elaborou-se uma síntese sobre a evolução histórica e doutrinária do cooperativismo, a fim de propiciar a compreensão sobre a dinâmica da cooperação existente na agricultura familiar e a articulação promovida pelas cooperativas em prol de auxiliar no processo de inclusão social dos agricultores familiares no território. As experiências mostram que tanto a Cooesperança quanto a La Choza representam importantes formas de fomento para a mudança de comportamento dos agricultores familiares, no sentido de agir pensando no coletivo e de buscar modos de melhorar a renda de suas famílias, bem como de conscientizar e de incentivar a mudança de hábitos da sociedade, em relação ao consumo de alimentos saudáveis. Infere-se que, por meio das atividades desenvolvidas, dos processos organizativos de produção e de comercialização e da capacidade de articular os agricultores familiares, essas cooperativas transformam-se em estratégia para o fortalecimento desses agricultores, produtores de alimentos orgânicos e biodinâmicos, contribuindo para alavancar a produção sustentável, para revigorar as redes no sentido horizontal, para gerar novas formas de organização da agricultura familiar e para promover o desenvolvimento social, econômico, cultural e ambiental.

Palavras-chave: Cooperativismo. Agricultura familiar. Agroecologia.

${ }^{1}$ Doutora em Desenvolvimento Regional. Professora do Curso de Administração da Universidade Federal da Fronteira Sul (UFFS), Campus Cerro Largo (RS). denise.fernandes@uffs.edu.br

2 Doutora em Geografia. Professora do Programa de Pós-Graduação em Desenvolvimento Regional (Mestrado e Doutorado) da Universidade de Santa Cruz do Sul (Unisc). erica@unisc.br 


\begin{abstract}
This article aims to describe organizing processes of cooperation developed in cooperatives of family farmers that adopt and/or encourage agroecological practices, from the organization of collective actions present in two distinct realities: first, the Cooperative Cooesperança, in Santa Maria, state of Rio Grande do Sul, Brazil; and second, the Cooperative La Choza in the county of General Rodriguez, Buenos Aires province, Argentina. To achieve it, is draws up an overview of the historical and doctrinal evolution of the cooperativism in order to facilitate the understanding of the dynamics of existing cooperation in family farming and the articulation promoted by cooperatives towards aid in the process of social inclusion of family farmers in the territory. The experiences show that both the Cooesperança as the La Choza represent important forms of motivate for the change of behavior of family farmers, to act thinking in the collective and to seek ways to improve the income of their families, as well as to raise awareness and to encourage the change of habits of the society, in relation to the consumption of healthy foods. It is inferred that, by means of activities undertaken, the organizational processes of production and commercialization and of the ability to articulate the family farmers, these cooperatives are transformed into strategy for strengthening these farmers, producers of organic and biodynamic food, contributing to leverage sustainable production, to reinvigorate the networks, horizontally, to generate new forms of organization of family farming and to promote social, economic, cultural and environmental development.
\end{abstract}

Keywords: Cooperativism. Family farming. Agroecology.

\title{
1 Introdução
}

O presente artigo aborda o cooperativismo e seus processos de evolução histórica e doutrinária, bem como a influência dessa doutrina nos processos organizativos, e o sistema de cooperação desenvolvido, atualmente, em duas realidades distintas: a primeira, da Cooperativa Cooesperança ${ }^{3}$, no município de Santa Maria, estado do Rio Grande do Sul, Brasil; e a segunda, da Cooperativa La Choza ${ }^{4}$, no município de General Rodriguez, província de Buenos Aires, Argentina.

\footnotetext{
${ }^{3}$ A Cooesperança (Cooperativa Mista dos Pequenos Produtores Rurais e Urbanos Vinculados ao Projeto Esperança Ltda.), criada em 29 de setembro de 1989, é uma Central que, juntamente com o Projeto Esperança, congrega e articula os grupos organizados e viabiliza a comercialização direta dos produtos produzidos pelos empreendimentos solidários do campo e da cidade, fortalecendo-os juntamente com todos os grupos, num novo modelo de cooperativismo, na proposta alternativa, solidária, transformadora, autogestionária e no desenvolvimento solidário, sustentável e territorial, na certeza de que Um Outro Cooperativismo é Possível (ARQUIDIOCESE DE SANTA MARIA, 2012, p. 9).

${ }^{4}$ La Choza (La Choza Cooperativa de Trabajo Limitada), respeitando os ciclos da natureza para produzir alimentos saudáveis, dedica-se à produção fruti-hortícola, à atividade no tambo e à elaboração de derivados do leite e, num viveiro, recuperando e reproduzindo plantas nativas da província de Buenos Aires para reflorestamento. Todas essas atividades são desenvolvidas de acordo com os princípios da agricultura biológico-dinâmica (FUNDACIÓN LA CHOZA, 2016a).
} 
Ressalta-se que tanto a Cooesperança como a La Choza caracterizam-se por dinamizarem mudanças nos territórios que ocupam, ao articular os agricultores familiares, incentivando-os a produzir alimentos orgânicos e biodinâmicos, respectivamente. Observa-se que ambas as cooperativas demonstram ter a capacidade de agregar seus cooperados, priorizando alternativas sustentáveis de produção de alimentos que ajudam a preservar o meio ambiente.

Assim, vislumbra-se que a atuação dessas cooperativas se mostra eficaz para a melhoria da qualidade de vida dos agricultores e de suas famílias, que no nível de renda como da integração na sociedade, bem como para atender à demanda do consumidor, dentre outras vantagens. Dessa forma, podem contribuir para a promoção de um desenvolvimento que abarque não só o aspecto econômico, mas também aspectos sociais, culturais e ambientais.

Diante dessa perspectiva, justifica-se a elaboração deste estudo, que tem como objetivo, tomando como base o cooperativismo, de descrever processos organizativos de cooperação desenvolvidos em cooperativas de agricultores familiares que adotam e/ou incentivam práticas agroecológicas.

Considerando o contexto histórico-doutrinário do cooperativismo e o processo de cooperação existente entre os agricultores familiares, busca-se, também, identificar os desafios para a construção de sustentabilidade no desenvolvimento territorial, e, ao especificar o caso da Cooesperança (Brasil) e da La Choza (Argentina), procura-se apresentar a transformação que está acontecendo e as possibilidades de mudança no meio rural, por meio da cooperação para a produção e para a comercialização dos alimentos orgânicos.

Para desenvolver este estudo e atingir esses objetivos propostos, optouse pela pesquisa descritiva de natureza qualitativa, porque "[...] tem o ambiente natural como sua fonte direta de dados e o pesquisador como seu principal instrumento" (LÜDKE; ANDRÉ, 1986, p. 11).

Como método de pesquisa, adotou-se o estudo de caso, pois "[...] se fundamenta na ideia de que a análise de uma unidade de determinado universo possibilita a compreensão da generalidade do mesmo, ou, pelo menos, o estabelecimento de bases para uma investigação posterior, mais sistemática e precisa" (GIL, 2008, p. 79). Neste caso, conforme já demonstrado, as unidades estudadas foram as cooperativas Cooesperança (no Brasil) e La Choza (na Argentina).

Para a coleta de dados, foram realizadas entrevistas com roteiros pré-determinados, nos âmbitos do local de comercialização (caso da Cooesperança) e da unidade de produção (caso da La Choza), isto é, onde os agricultores familiares desenvolvem parte de suas atividades. Além disso, foram feitas observações sistemáticas/não participantes pelas pesquisadoras, ou seja, como espectadoras, presenciando os fatos sem participar deles. Em relação a esses procedimentos técnicos, Gerhardt et al. (2009) destacam que, por meio da entrevista, pode-se dar a oportunidade de o entrevistado falar, livre e naturalmente, sobre o tema central e outros assuntos que possam surgir como desdobramentos da temática principal, enquanto que, por meio das observações, é possível visualizar as práticas desenvolvidas. Portanto, entende-se que tais procedimentos podem contri- 
buir para uma descrição mais detalhada e precisa dos fenômenos que ocorrem nas cooperativas pesquisadas.

Dessa forma, este estudo caracteriza-se como uma pesquisa descritiva de natureza qualitativa, que tem como método de investigação o estudo de caso e utiliza a entrevista semiestruturada e a observação sistemática/não participante como instrumentos para a coleta de dados.

Enfim, para demonstrar o que se propõe, estruturou-se este artigo em sete seções: nesta introdução, apresentam-se as linhas gerais sobre o tema, os objetivos e os aspectos metodológicos; na segunda seção, abordam a evolução histórica e doutrinária do cooperativismo no mundo; na terceira seção, tratam do cooperativismo na América Latina; na quarta seção, enfocam os aspectos do cooperativismo no Brasil e na Argentina; a quinta seção, trazem o contexto de atividades desenvolvidas pela Cooesperança; a sexta seção mostra a realidade do trabalho realizado pela La Choza, e, por fim, na sétima e última seção, são apresentadas as considerações finais.

\section{A evolução histórica da doutrina cooperativista no mundo}

Nos primórdios da humanidade, a solidariedade aflorou no ser humano, em virtude da necessidade de sobreviver num ambiente hostil e suprir suas necessidades básicas de abrigo e alimento. Enfrentar feras, caçar e pescar foram algumas atividades nas quais o homem começou a experimentar as vantagens da cooperação (CENZI, 2012).

A história da humanidade apresenta inúmeros exemplos de efetiva congregação de pessoas com o fim de se auxiliarem mutuamente. Os povos nômades se uniam para coletar e caçar. Alguns povos asiáticos, na Pré-História, juntavamse para pastorear e/ou para cultivar lavouras. Os indígenas se agrupavam para caçar, pescar e guerrear (CENZI, 2012).

Ideias cooperativistas eram experimentadas no antigo Egito, por meio da reunião de agricultores escravos, com incentivo do Estado; e, na Grécia, cidadãos livres e escravos se reuniam para garantir enterros decentes, e carpinteiros e serralheiros, reunidos, formavam os colégios (RECH, 2000).

Um marco importante nesse processo histórico dá-se no ano de 1844, no bairro de Rochdale, em Manchester, na Inglaterra, com a criação da primeira cooperativa formal de trabalhadores (28 tecelões).

Uma cooperativa de consumo, resultado de uma luta para superar o capitalismo, cujos princípios ${ }^{5}$ serviram de referencial para o movimento cooperativista no mundo (PINHO, 1966b; RECH, 2000).

\footnotetext{
${ }^{5}$ Os princípios básicos de Rochdale foram reformulados por ocasião da II Assembleia Geral da $\mathrm{ACl}$, realizada em 1995, na cidade Manchester/Inglaterra, mantendo, no entanto, sua essência original. Atualmente, os princípios são os seguintes: adesão livre e voluntária, controle democrático pelos membros, participação econômica dos membros, autonomia e independência, educação, formação e informação, cooperação entre cooperativas e compromisso com a comunidade (COOPERATIVAS DE LAS AMÉRICAS, 2017).
} 
Na década de 1880, Charles Gide ${ }^{6}$ inicia a sistematização da doutrina cooperativista, que tem como conteúdo principal, segundo Pinho (1966b, p. 30), a proposta de "[...] corrigir as injustiças sociais, os males do ambiente econômicosocial, através da associação dos consumidores em cooperativas".

Nessa proposta, evidencia-se o relevante papel do consumidor, pois é natural concluir que todas as pessoas inseridas em uma sociedade são consumidoras. Diante disso, ressalta-se que:

O consumidor é o objetivo último da doutrina cooperativista e, também, o instrumento de reforma da sociedade. De fato, enquanto o capitalismo dá primazia ao capitalista e o socialismo ao proletariado, o cooperativismo coloca o consumidor como fim de toda atividade econômica, afirmando que, assim como na ordem política a soberania pertence ao cidadão, na ordem cooperativa a hegemonia cabe ao consumidor (PINHO, 1966b, p. 31).

Desse momento histórico, importa destacar que, segundo Pinho (1966b), além de dedicar sua vida ao estudo e à sistematização da doutrina cooperativista, Gide pregava a República Cooperativa7 e enumerou as doze virtudes do cooperativismo (Quadro 1), que se mantêm atuais nos dias de hoje:

\section{Quadro 1 - As 12 virtudes da doutrina cooperativista}

\begin{tabular}{|l|l|}
\hline \multicolumn{1}{|c|}{12 virtudes } & \multicolumn{1}{c|}{ Objetivos } \\
\hline 1. Viver melhor & $\begin{array}{l}\text { - Solucionar coletivamente os problemas e, por meio do } \\
\text { auxílio-mútuo, conseguir melhor nível de vida. }\end{array}$ \\
\hline 2. Pagar a dinheiro & $\begin{array}{l}\text { - Evitar as dívidas, porque o endividamento é "uma das } \\
\text { formas de escravidão". }\end{array}$ \\
\hline $\begin{array}{l}\text { 3. Poupar sem } \\
\text { sofrimento }\end{array}$ & $\begin{array}{l}\text { - Economizar, sem sacrificar a satisfação das } \\
\text { necessidades, por meio da devolução dos ganhos, sob } \\
\text { a forma de retorno dos excedentes, proporcionalmente } \\
\text { às operações realizadas pelos sócios na cooperativa. }\end{array}$ \\
\hline $\begin{array}{l}\text { 4. Suprimir os } \\
\text { parasitas }\end{array}$ & $\begin{array}{l}\text { - Eliminar os intermediários de maneira a se reduzir } \\
\text { ao mínimo os órgãos de transmissão de riquezas do } \\
\text { produtor ao consumidor. }\end{array}$ \\
\hline $\begin{array}{l}\text { 5. Combater o } \\
\text { alcoolismo }\end{array}$ & $\begin{array}{l}\text { - Evitar vícios e viver com saúde, finalidade educativa já } \\
\text { acentuada pelos Pioneiros de Rochdale. }\end{array}$ \\
\hline
\end{tabular}

(Continua)

6 Charles Gide (1847-1932) - francês, professor universitário, é conhecido mundialmente por suas obras sobre economia, política e cooperativismo. Fundador da 'Escola de Nimes', na França, que muito contribuiu com a produção do conhecimento sobre o cooperativismo mundial (BÜTTENBENDER, 2008, p. 22).

7 Charles Gide vislumbrou "[...] a cooperativização integral da sociedade, partindo das cooperativas de consumo para chegar, por etapas sucessivas, às cooperativas de produção industrial e agrícola. É o seu célebre 'Programa em Três Etapas' que permitirá atingir a 'República Cooperativista', qualificada de utópica por alguns cooperativistas, e defendida com ardor por outros" (PINHO, 1966a, p. 56). 


\begin{tabular}{|l|l|}
\hline \multicolumn{1}{|c|}{12 virtudes } & \multicolumn{1}{c|}{ Objetivos } \\
\hline $\begin{array}{l}\text { 6. Integrar as } \\
\text { mulheres nas } \\
\text { questões sociais }\end{array}$ & $\begin{array}{l}\text { - Obter a participação feminina, já que são elas que } \\
\text { cuidam do lar e fazem as compras; portanto, devem } \\
\text { conhecer os problemas do consumo e das cooperativas } \\
\text { de consumo. }\end{array}$ \\
\hline $\begin{array}{l}\text { 7. Educar } \\
\text { economicamente o } \\
\text { povo }\end{array}$ & $\begin{array}{l}\text { - Tornar homens e mulheres aptos/capacitados para a } \\
\text { autogestão econômica e política. }\end{array}$ \\
\hline $\begin{array}{l}\text { 8. Facilitar a } \\
\text { todos o acesso à } \\
\text { propriedade }\end{array}$ & $\begin{array}{l}\text { - Conquistar os meios de produção, por meio da união } \\
\text { de esforços, ou seja, coletivamente. }\end{array}$ \\
\hline $\begin{array}{l}\text { 9. Reconstituir } \\
\text { uma propriedade } \\
\text { coletiva }\end{array}$ & $\begin{array}{l}\text { - Formar um patrimônio cooperativo, que é coletivo } \\
\text { e está a serviço de um interesse geral e permanente, } \\
\text { "acima de nossas existências efêmeras". }\end{array}$ \\
\hline $\begin{array}{l}\text { 10. Estabelecer o } \\
\text { justo preço }\end{array}$ & $\begin{array}{l}\text { - Remunerar convenientemente todo trabalho } \\
\text { consagrado à produção, inclusive o trabalho de direção } \\
\text { e os trabalhos intelectuais preparatórios, definindo os } \\
\text { preços sem motivação especuladora. }\end{array}$ \\
\hline $\begin{array}{l}\text { 11. Eliminar o lucro } \\
\text { capitalista }\end{array}$ & $\begin{array}{l}\text { - Criar a preocupação com a satisfação das necessidades } \\
\text { dos homens e não com a obtenção de lucros. }\end{array}$ \\
\hline $\begin{array}{l}\text { 12. Abolir os } \\
\text { conflitos }\end{array}$ & $\begin{array}{l}\text { - Tornar-se seu próprio fornecedor: na cooperativa } \\
\text { de consumo, o consumidor torna-se seu próprio } \\
\text { fornecedor; na cooperativa de produção, o operário } \\
\text { torna-se seu próprio patrão; na cooperativa de crédito, } \\
\text { o sacador torna-se seu próprio sacado; na cooperativa } \\
\text { de habitação, o locatário torna-se seu próprio locador, e } \\
\text { assim por diante, de modo que toda disputa cessa pela } \\
\text { fusão dos inimigos, ou melhor, "o combate cessa por } \\
\text { falta de combatentes". }\end{array}$ \\
\hline
\end{tabular}

Fonte: Elaborado pelas autoras, a partir de Pinho (1966b, p. 34-35).

Concomitantemente a esse início da sistematização da doutrina cooperativista, cabe destacar que, em 1895, em Londres, na Inglaterra, foi criada a Aliança Cooperativa Internacional $(\mathrm{ACl})^{8}$ - órgão máximo do cooperativismo mundial - que pregava a continuação da obra dos Pioneiros de Rochdale e que reunia associações cooperativas de diversos países, congregando-as desde que tivessem a intenção de melhorar as condições econômicas e sociais de seus membros, que primassem pelo auxílio-mútuo e que se pautassem pelos mesmos princípios de Rochdale (PINHO, 1966b; CENZI, 2012).

Avançando em busca da atualização e do aprimoramento da doutrina cooperativista, destacam-se alguns dos principais precursores e estudiosos (Quadro 2) do cooperativismo, conforme Pinho (1977) e Vilchez (1986):

\footnotetext{
${ }^{8}$ Aliança Cooperativa Internacional $(\mathrm{ACl})$ é a entidade mais representativa do cooperativismo no mundo e tem como função primordial preservar e defender os princípios cooperativistas. Atualmente, sua sede está localizada em Bruxelas, na Bélgica, e se organiza por intermédio de quatro sedes continentais: África, América, Ásia e Europa (COOPERATIVA DE LAS AMÉRICAS, 2016a).
} 
Quadro 2 - Precursores do cooperativismo

\begin{tabular}{|l|l|}
\hline \multicolumn{1}{|c|}{$\begin{array}{c}\text { Precursores/ } \\
\text { estudiosos }\end{array}$} & \multicolumn{1}{c|}{ Origem e feitos na área do cooperativismo } \\
\hline $\begin{array}{l}\text { John Bellers } \\
\text { (1654-1725) }\end{array}$ & $\begin{array}{l}\text { Inglês, iniciou organizações cooperativas de trabalho } \\
\text { visando eliminar o lucro pretendido pelas indústrias. }\end{array}$ \\
\hline $\begin{array}{l}\text { Robert Owen } \\
\text { (1772-1858) }\end{array}$ & $\begin{array}{l}\text { Inglês, é considerado o pai do cooperativismo; entendia } \\
\text { que as injustiças sociais eram decorrentes do estímulo ao } \\
\text { lucro e à concorrência. }\end{array}$ \\
\hline $\begin{array}{l}\text { Philippe Buchez } \\
\text { (1792-1865) }\end{array}$ & $\begin{array}{l}\text { Belga, estimulou a autogestão nas cooperativas e, na } \\
\text { França, organizou cooperativas de produção. }\end{array}$ \\
\hline $\begin{array}{l}\text { Luis Blanc } \\
\text { (1812-1882) }\end{array}$ & $\begin{array}{l}\text { Francês, destacou-se na política, defendendo causas como } \\
\text { o direito ao trabalho e a liberdade baseada na educação } \\
\text { (moral e ética) da sociedade. }\end{array}$ \\
\hline $\begin{array}{l}\text { Friedrich } \\
\text { Raiffeisen } \\
\text { (1818-1888) }\end{array}$ & $\begin{array}{l}\text { Alemão, julgava que o amor ao próximo e o auxílio mútuo } \\
\text { eram a solução para resolver as questões sociais. Sua } \\
\text { paixão pela agricultura levou-o a buscar alternativas para } \\
\text { resolver os problemas de obtenção de crédito agrícola e, } \\
\text { para isso, organizou cooperativas de crédito. }\end{array}$ \\
\hline $\begin{array}{l}\text { Bernard Lavergne } \\
\text { (1884-1975) }\end{array}$ & $\begin{array}{l}\text { Francês, acreditava que o cooperativismo sucederia a } \\
\text { ordem capitalista, pois representava a terceira via entre o } \\
\text { coletivismo estatal e o capitalismo. }\end{array}$ \\
\hline $\begin{array}{l}\text { Ernest Poisson } \\
\text { (1882-1942) }\end{array}$ & $\begin{array}{l}\text { Francês, proclamava a soberania do consumidor } \\
\text { e, ao contrário de Gide, entendia que não havia } \\
\text { incompatibilidade entre o marxismo e o cooperativismo. }\end{array}$ \\
\hline $\begin{array}{l}\text { Georges Lasserre } \\
\text { (1902-1985) }\end{array}$ & $\begin{array}{l}\text { Francês, vislumbrava a possibilidade de concretizar a } \\
\text { República Cooperativa, mas reconhecia as barreiras } \\
\text { impostas pelo capitalismo à difusão do cooperativismo. }\end{array}$ \\
\hline Fonte: Elaborado pelas autoras, a partir de Pinho (1977) Vilchez (1986).
\end{tabular}

Fonte: Elaborado pelas autoras, a partir de Pinho (1977) e Vilchez (1986).

George Fauquet ${ }^{9}$, por sua vez, discordava de Gide quanto à cooperativização integral da sociedade e, por volta de 1935, externou que as cooperativas não conseguiriam concretizar as reformas socioeconômicas apregoadas na República Cooperativa. E ainda, que, no máximo, poderiam compor um setor - o Setor Cooperativo - que abrangeria todas as formas de cooperativas: de consumo, de produção, de crédito, etc. (PINHO, 1966b; VILCHEZ, 1986).

A linha de pensamento de Fauquet reduz, portanto, as possibilidades de reformulações socioeconômicas cooperativistas exclusivamente às atividades do setor cooperativo, o que, segundo Pinho (1966b, p. 36) se deve ao fato de que as cooperativas "[...] dominam essencialmente os extremos inicial e final do processo econômico [...]". Dessa forma, visualizando-se a cadeia produtiva de alimentos orgânicos e/ou biodinâmicos na agricultura familiar, infere-se que, estando no

\footnotetext{
${ }^{9}$ Um dos cooperativistas (1873-1953) que mais influenciou no pensamento cooperativo contemporâneo. Seu livro 'Le secteur coopératif' foi traduzido em diversos idiomas. Foi chefe do departamento de cooperação da Organização Internacional do Trabalho (VILCHEZ, 1986, p. 168-169).
} 
setor cooperativista, produzindo alimentos (cooperativas de produção), os agricultores familiares estariam inseridos no extremo inicial, e os consumidores, adquirindo bens e serviços (cooperativas de consumo), no extremo final, enquanto as indústrias de transformação (empresas capitalistas) ocupariam a zona intermediária.

Há que se considerar que é preciso encontrar um meio-termo entre as propostas de Gide e de Fauquet, porque, mesmo estando no extremo inicial, ou seja, na produção de alimentos (de acordo com a proposta de Fauquet), os agricultores familiares não deixam de ser consumidores (conforme a teoria de Gide), pois compram insumos - adubos, sementes, mudas, etc. Nesse contexto doutrinário, considerando a diversidade de variáveis, identificar o papel dos agricultores familiares é um exercício difícil, mas importante. No entanto, mais importante que determinar uma posição nesse cenário é encontrar alternativas possíveis de cooperar para o desenvolvimento de atividades mais justas e solidárias.

Nessa síntese, verifica-se que a doutrina cooperativista começa a ser sistematizada pós-Rochdale, tendo por premissa maior corrigir as injustiças sociais e, com base nas conclusões de Pinho (1966b), avançando sob a batuta de doutrinadores divididos em dois grupos principais: os que defendem, inspirados em Gide, a "República Cooperativa", ou seja, a reforma pacífica e integral da sociedade por meio das cooperativas; e os que sustentam, inspirados em Fauquet, que o cooperativismo limite-se a reformas socioeconômicas em um setor da sociedade, o "Setor Cooperativo".

\section{0 cooperativismo na América Latina}

Na América Latina, as primeiras experiências cooperativas são atribuídas aos Incas, com suas unidades locais: os ayllus, baseadas no trabalho coletivo e em vínculos de sangue, ou seja, familiar, e aos Astecas, com os calpulli, que se dedicavam a desenvolver a atividade agrícola com alto grau de solidariedade e cooperação tanto no trabalho como na vida em coletividade (RECH, 2000).

O cenário latino-americano, no início do século XX, possuía muitas semeIhanças com o cenário dos tecelões de Rochdale e com o cenário vivenciado por Raiffeisen, nos anos de 1847-1848, na Alemanha: muita dificuldade financeira e muita miséria oportunizando a formação concreta de processos associativos e do desenvolvimento das práticas de cooperação para a produção e para o consumo (PINHO, 1966a).

Por ocasião da chegada dos imigrantes europeus no meio rural, na América Latina, essas práticas ganharam expressão e, a partir delas, potencializou-se o desenvolvimento da população rural (PINHO, 1966a; OBSCHATKO; BASAÑES; MARTINI, 2011). Muitos países latino-americanos, conforme as leis promulgadas (Quadro 3), todas de inspiração rochdaleana, iniciaram um processo de legitimação do cooperativismo, caracterizando-as de acordo com os princípios de Rochdale, mas com determinadas especificidades peculiares em cada país: 
Quadro 3 - Caracterização das cooperativas na América Latina

\begin{tabular}{|c|c|}
\hline País / Lei & Características \\
\hline $\begin{array}{l}\text { Argentina } \\
\text { Lei Cooperativa } \\
\text { Argentina no } \\
\text { 11.388, de } \\
\text { 20/12/1926. } \\
\text { (Art. 2ㅇ) }\end{array}$ & $\begin{array}{l}\text { 1) número ilimitado de sócios e quotas-partes; } \\
\text { 2) indivisibilidade e inacessibilidade das quotas-partes; } \\
\text { 3) direito a um voto por sócio apenas; } \\
\text { 4) prestação de serviço somente aos sócios; } \\
\text { 5) distribuição de retorno; } \\
\text { 6) proibição da propaganda de ideias políticas, religiosas ou } \\
\text { de países. }\end{array}$ \\
\hline $\begin{array}{l}\text { México } \\
\text { Lei Geral das } \\
\text { Sociedades } \\
\text { Cooperativas, } \\
\text { de } \\
11 / 01 / 1938 \\
\text { (Art. 1ㅇ) }\end{array}$ & $\begin{array}{l}\text { 1) ser integrada por trabalhadores (cooperativas de } \\
\text { produtores) ou de membros da sociedade que utilizem os } \\
\text { serviços que esta distribui (cooperativa de consumidores); } \\
\text { 2) usufruírem os seus membros de igualdade de direitos e } \\
\text { de obrigações; } \\
\text { 3) funcionar com número variável de sócios, nunca inferior } \\
\text { a dez; } \\
\text { 4) ter capital variável e duração indeterminada; } \\
\text { 5) conceder a cada sócio apenas um voto; } \\
\text { 6) não objetivar lucros; } \\
\text { 7) buscar a melhoria econômica e social de seus associados } \\
\text { mediante a ação conjunta destes em uma obra coletiva; } \\
\text { 8) dividir rendimentos entre os sócios proporcionalmente } \\
\text { ao tempo de trabalho de cada um (cooperativas de } \\
\text { produção) e de acordo com o montante de operações } \\
\text { realizadas com a sociedade (cooperativas de consumo). }\end{array}$ \\
\hline $\begin{array}{l}\text { Bolívia } \\
\text { Lei Geral das } \\
\text { Sociedades } \\
\text { Cooperativas, } \\
\text { de } \\
13 / 09 / 1958 \\
\text { (Art. } 1 \text { ㅇ) }\end{array}$ & $\begin{array}{l}\text { 1) todos os sócios têm igualdade de direitos e obrigações; } \\
\text { 2) a sociedade é regida pelo princípio do controle } \\
\text { democrático, e cada sócio tem direito a um voto; } \\
\text { 3) as contribuições individuais (capitais, bens, direitos, } \\
\text { trabalho) constituem propriedade comum, com funções } \\
\text { de serviço social ou de utilidade pública; } \\
\text { 4) o objetivo da sociedade não é o lucro, mas sim a ação } \\
\text { conjunta dos sócios para a melhoria econômica e social e } \\
\text { para estender os benefícios da educação cooperativa e a } \\
\text { assistência social à comunidade; } \\
\text { 5) a distribuição dos excedentes será efetuada de acordo } \\
\text { com o trabalho realizado nas cooperativas industriais, } \\
\text { agrícolas ou de serviços; de acordo com o montante } \\
\text { de operações, nas de consumo e crédito; conforme } \\
\text { o trabalho, montante de operações, consumo ou } \\
\text { aproveitamento, nas de educação; } \\
\text { 6) juros limitados ao capital. }\end{array}$ \\
\hline
\end{tabular}

(Continua) 


\begin{tabular}{|c|c|}
\hline País / Lei & Características \\
\hline $\begin{array}{l}\text { Brasil } \\
\text { Decreto no } \\
22.239 \text {, de } \\
\text { 19/12/1932. } \\
\text { (Art. 2ㅇ) }\end{array}$ & $\begin{array}{l}\text { 1) variabilidade do capital social para aqueles que se } \\
\text { constituem com capital social declarado; } \\
\text { 2) não limitação de número de associados, mas no mínimo } \\
\text { sete. } \\
\text { 3) limitação do valor da soma de quotas-partes de capital } \\
\text { social que cada associado poderá possuir; } \\
\text { 4) inacessibilidade das quotas-partes do capital social por } \\
\text { parte de terceiros estranhos à sociedade, ainda que em } \\
\text { 'causa mortis'; } \\
\text { 5) 'quórum' para deliberar a assembleia geral, fundado no } \\
\text { número de associados presentes à reunião; } \\
\text { 6) distribuição dos lucros ou sobras proporcionalmente } \\
\text { ao valor das operações efetuadas pelo associado com } \\
\text { a sociedade, podendo ser atribuído ao capital social } \\
\text { um juro fixo, não maior que cinco por cento ao ano, } \\
\text { previamente estabelecido nos estatutos; } \\
\text { 7) dedução de porcentagens para o fundo de reserva, não } \\
\text { inferior a 10\%; } \\
\text { 8) indivisibilidade do fundo de reserva entre os associados, } \\
\text { mesmo em caso de dissolução da sociedade; } \\
\text { 9) singularidade de voto nas deliberações, isto é, cada } \\
\text { associado tem direito a um voto; } \\
\text { 10) área de ação determinada. }\end{array}$ \\
\hline
\end{tabular}

Fonte: Elaborado pelas autoras, a partir de Pinho (1966b, p. 46-48).

Atualmente, a Cooperativas de las Américas (antes ACl-Américas), vinculada a ACl-Internacional e estabelecida, desde 1990, em San José, na Costa Rica, representa o sistema cooperativo no continente americano e tem por objetivo principal:

Promover o reposicionamento do modelo cooperativo no novo entorno econômico, político, social e comercial, apoiando as organizações-membros da $\mathrm{ACl}$ nas Américas na difusão e defesa da identidade cooperativa, a promoção dos negócios e o desenvolvimento do recurso humano. (COOPERATIVAS DE LAS AMÉRICAS, 2016b, tradução nossa).

Importante destacar, de acordo com Cenzi (2012, p. 41), que "O cooperativismo na América, assim como no resto do mundo, tem o mesmo histórico e a mesma base de formação, pois, em todos os lugares onde existe uma cooperativa, os princípios adotados centram-se no modelo universal". Contudo, é preciso frisar que não há um modelo exclusivo de cooperativa; entretanto, os princípios básicos e o modelo da primeira cooperativa formal de trabalhadores de Rochdale representam um referencial para a criação de outras novas cooperativas em qualquer país do mundo, inclusive nos da América Latina, caso de Brasil e Argentina.

\section{Processo de surgimento e organização cooperativista no Brasil e na Argentina}

No Brasil, a forma de organização cooperativista estruturou-se a partir da chegada dos imigrantes europeus, principalmente no período entre 1824 e 1920, 
porque, ao chegarem, enfrentaram muitas dificuldades - de todas as ordens - e encontraram na cooperação e na solidariedade a possibilidade de desenvolverem suas atividades.

De acordo com Cenzi (2012), o surgimento das cooperativas efetivou-se, primeiramente, nos estados litorâneos, do sul ao nordeste. Isso ocorreu em função da grande massa de imigrantes que aportava no Brasil desde meados do século XIX. Na década de 1930, houve ampla disseminação e aparecimento de cooperativas no Brasil - um verdadeiro surto de cooperativas - muito graças à criação da lei básica do cooperativismo, por meio do Decreto 22.239, de 19 de dezembro de 1932, fortemente influenciada pela experiência dos imigrantes alemães, italianos e japoneses.

Apesar disso, o governo de Getúlio Vargas, em 1934, por meio do Decreto 24.647, de 10 de julho, revoga o decreto anterior e cria uma vinculação e controle realizados pelo Estado. Essa interferência do Estado, intervindo no controle das cooperativas, por meio de um processo centralizador e paternalista, perdurou até 1988, quando a atual constituição estabeleceu um novo sistema de gestão cooperativa, a autogestão. Segundo Cenzi (2012, p. 48), a implantação desse novo sistema "[...] refletiu bastante no crescimento, em especial das cooperativas de crédito e de trabalho".

Faz-se necessário aclarar que, para chegar ao modelo atual, inúmeras foram as dificuldades enfrentadas. Rech (2000) enfatiza que, durante o regime militar, por meio da Lei 5.764, de 16 de dezembro de 1971, foram impostas severas restrições nas estruturas organizacionais das cooperativas, o que dificultou o desenvolvimento do modelo cooperativista no Brasil.

Na década de 1980, movimentos sociais mobilizaram o país, visando à transformação da forma de governo (da ditadura militar para a democracia). Mas o regime militar desenvolvia um controle rigoroso das atividades, inclusive das cooperativas, dos sindicatos, de grupos sociais organizados que se articulavam em prol da democracia como forma de resistência, a fim de que pudessem continuar existindo.

A democratização tornou-se mais efetiva com a execução de fóruns de debates, promovidos pelo movimento das associações e cooperativas no meio rural e pela motivação de diversos movimentos sociais em favor de ações coletivas de desenvolvimento. Gohn (2008, p. 446) corrobora essa argumentação ao esclarecer que "No Brasil, a partir dos anos 90, a tendência dos grupos sociais organizados se articularem em redes e criarem fóruns a partir dessas redes passou a imperar como modismo, de um lado, e, 'exigência para sobrevivência', de outro" (grifo das autoras).

Para explicar os movimentos sociais e suas ações, nas décadas de 1980 e 1990, diversas teorias foram elaboradas, o que, de certa forma, serve para desvendar a conjuntura do associativismo civil no Brasil. A respeito dessas teorias, ressalta-se que: 
Elas buscam explicar o novo cenário de associativismo civil, principalmente no Brasil. Políticas de identidade têm sido construídas por políticas públicas advindas de governos, em vários países latino-americanos, na última década. Essas políticas buscam 'incluir' grupos e associações tidos como vulneráveis (GOHN, 2008, p. 452).

No entanto, apesar de essas políticas públicas terem a "boa intenção" de incluir grupos e associações vulneráveis, Rech (2000) critica tais políticas ao colocar em discussão o modelo cooperativista adotado no Brasil:

\begin{abstract}
Não estamos descartando a necessidade da observação de uma estrutura básica do modelo cooperativista. O que estamos fazendo é colocando em discussão o modelo adotado no Brasil e suas características, principalmente porque o que conhecemos é a proposta de uma cooperativa que apenas venha resolver algumas distorções que o sistema capitalista apresenta, dificultando inovações e, principalmente, evitando que as comunidades caminhem em direção a uma proposta de cooperativismo autogestionário, participativo e democrático-popular (RECH, 2000, p. 21, grifo do autor).
\end{abstract}

Além dessas limitações do modelo cooperativista brasileiro citadas por Rech, que evidenciam a necessidade de aprimoramento desse modelo, o processo de empobrecimento gerado pela crise do emprego, iniciada por volta de 1980, orientou a implementação de novas políticas. Estas foram desenvolvidas no Brasil, com a intenção de acabar ou, pelo menos, reduzir a exclusão social.

O elo entre a possibilidade de avanços do modelo cooperativista brasileiro e a necessidade de uma massa de trabalhadores, excluída socialmente, sobreviver em um momento de crise verifica-se na argumentação de Singer (2004, p. 3):

Como defesa contra a exclusão social e a queda na indigência, as vítimas da crise buscam sua inserção na produção social através de variadas formas de trabalho autônomo, individuais e coletivas. Quando coletivas, elas optam, quase sempre, pela autogestão, ou seja, pela administração participativa, democrática, dos empreendimentos. São estes os que constituem a economia solidária.

Nesse contexto, dentre outras políticas públicas, destaca-se a criação, em junho de 2003, da Secretaria Nacional de Economia Solidária (SENAES), agregada ao Ministério do Trabalho e do Emprego (MTE). A criação dessa secretaria, segundo Singer (2004, p. 3), "[...] representou uma ampliação significativa do âmbito de responsabilidades do MTE, que passa a incluir o cooperativismo e associativismo urbano (já que pelo rural continua responsável o Ministério da Agricultura)".

A construção de uma política participativa conduzida pela SENAES propunha reduzir as desigualdades sociais, fomentar a economia solidária e possibilitar o desenvolvimento de associações e a criação de cooperativas autogestionárias, visando à superação da pobreza extrema no Brasil (SINGER, 2004).

Contudo, percebe-se um momento de (re)adequações das associações e cooperativas em relação à economia solidária e à legislação, principalmente na Lei $n$ o 12.690 , de 19 de julho de 2012, que dispõe sobre a organização e o funcio- 
namento das Cooperativas de Trabalho e institui o Programa Nacional de Fomento às Cooperativas de Trabalho (PRONACOOP).

Em resumo, essas políticas públicas revelam novas perspectivas relacionadas à estruturação alternativa de cooperativas com modelo de autogestão e ao desenvolvimento coletivo de forma solidária, como possibilidade para a permanência dos agricultores familiares no mercado, tudo em prol do desenvolvimento sustentável. Por outro lado, na Argentina, antes mesmo do estabelecimento do marco legal cooperativista, em 1926, registram-se movimentos cooperativistas importantes. Considera-se que a criação por colonos suíços-alemães da Cooperativa Frederico Meiners, em Esperanza, província de Santa Fé, em 1878, marca a origem do cooperativismo no país (OBSCHATKO; BASAÑES; MARTINI, 2011).

Referindo-se à primeira aproximação do cooperativismo no meio rural argentino, Carricart (2012) aponta um grupo de colonos franceses como responsáveis pela criação, em 1898, da Cooperativa El Progreso, que visava amenizar prejuízos provocados por quedas de granizo na região de Pigüé, ao sul da província de Buenos Aires. No entanto, o autor afirma que a primeira cooperativa agrária propriamente dita foi a Liga Agrícola Ganadera de Junín, ao norte da província de Buenos Aires, criada em 1904.

As ações coletivas dos imigrantes reduziram as dificuldades encontradas nos novos territórios, e, com a criação de uma nova lógica organizativa coletiva para o desenvolvimento de suas atividades, apresentaram evidências de que a participação democrática atenderia aos interesses dos associados (OBSCHATKO; BASAÑES; MARTINI, 2011). Verifica-se, portanto, que, assim como no Brasil, o começo dos processos associativos/cooperativos na Argentina aconteceu por influência de experiências de imigrantes europeus. Naquele país, as bases legais das cooperativas foram estabelecidas no ano de 1926, quando foi sancionada a Lei no 11.388, regulamentada em 1927, que, apesar de primitiva, não impediu a constituição das primeiras cooperativas. Essa lei permaneceu vigente até 2 de maio de 1973, quando foi sancionada a Lei no 20.347, que consolida novas normas e regras para as cooperativas agropecuárias de consumo, de crédito, de trabalho, de serviços públicos, etc. (OBSCHATKO; BASAÑES; MARTINI, 2011; CARRICART, 2012).

A consolidação da legislação, somada à orientação de líderes experientes e à disseminação da doutrina cooperativista, auxiliou a transformar o movimento cooperativo argentino em um dos mais avançados da América Latina. Destaca-se o avanço das cooperativas agrícolas que se desenvolveram "[...] sob a forma de cooperativas de produção agropecuária, de produção industrial ligada à agricultura, de seguros agrícolas, mistas, etc." (PINHO, 1966a, p. 74).

No período de 1984 a 1989, verificou-se uma mudança significativa na dinâmica cooperativa, porque o governo viu no movimento cooperativista argentino uma alternativa organizacional eficaz e de enfrentamento no mercado. Por isso, por intermédio da Secretaría de Acción Cooperativa, desenvolveu programas que estimulavam o desenvolvimento das cooperativas existentes e a criação 
de novas entidades no setor (OBSCHATKO; BASAÑES; MARTINI, 2011), o que, de certa forma, ajudaria a sustentar a reação de uma massa de desempregados pós-crise de 2002.

A Argentina vivenciou, desde o princípio de um momento histórico conduzido pela ditadura militar (1976-1983), até o ano de 2001, profundas transformações nas condições materiais e subjetivas das famílias pertencentes a distintas classes sociais. Essas mudanças acentuadas originaram-se do novo modelo de acumulação de capital, sustentado pela valorização financeira imposta pelo Estado (representado tanto pela ditadura militar, até 1983, quanto pelos governos democráticos até 2001). Esse contexto impôs graves dificuldades à população das classes menos favorecidas, o que culminou, em 2002, numa gravíssima crise econômica, social, do sistema político e das representações institucionais argentinas (BASUALDO, 2011). Essa crise deflagrou um processo de empobrecimento da população e levou muitos trabalhadores desempregados, visando à manutenção dos empregos, a desenvolverem cooperativas de trabalho para, dessa forma, garantirem a continuidade de aproximadamente 180 antigas empresas (OBSCHATKO; BASAÑES; MARTINI, 2011).

A partir do ano de 2003, o governo argentino adotou novas políticas de estímulo ao associativismo e às cooperativas do setor rural como suporte para o desenvolvimento de agricultores familiares que estavam em situação de exclusão social. Essas políticas, de modo geral, provocaram uma notável formação de diversos tipos de associações, as quais visavam receber, basicamente, capacitação, assistência técnica e financiamento. Concomitante a essas ações governamentais, estabeleceu-se, em dezembro de 2005, o Foro Nacional de Agricultura Familiar (FoNAF) que estimulou a incorporação de grande número de associações de todo o país. No entanto, apesar desses esforços integrados, constatou-se que houve uma reduzida constituição/criação de cooperativas ou associações formais em relação às informais que buscavam adesão ao Foro (OBSCHATKO; BASAÑES; MARTINI, 2011).

São evidenciadas semelhanças nos processos históricos do cooperativismo argentino e brasileiro, porém ressalta-se uma diferença marcante: é que, no Brasil, o Estado desenvolveu uma condução rigorosa na formação das cooperativas, enquanto que, na Argentina, a sociedade integrada estabeleceu estruturas de concretização de associações e cooperativas em prol da necessidade coletiva. Tal conclusão, além de comprovar-se nesta apresentação da evolução histórica do cooperativismo nesses países, é validada pela afirmação de Devoto e Boris (2004, p. 27):

Enquanto no Brasil o primeiro que salta aos olhos é o Estado, na Argentina é a sociedade. Neste país, a despeito de todos os seus recentes fracassos, construiu-se ao longo do processo histórico uma sociedade mais integrada (mais estruturada se preferir) do que a brasileira, com uma forte presença de mecanismos sociais autônomos em relação ao Estado. 
Contudo, se, por um lado, a participação do Estado diferencia-se, na dimensão histórica que envolve o cooperativismo no Brasil e na Argentina, por outro, verificam-se parâmetros comuns (definições e princípios rochdaleanos) na base de formação das cooperativas. Outrossim, em ambos os países, revelam-se evidências de que as associações e cooperativas são formas de articulação importantes, que viabilizam a afirmação de sentimentos contrários à hegemonia por parte de grupos sociais que se encontram em situação de exclusão nessas sociedades de classes.

No intuito de corroborar essa argumentação, apresentam-se dois casos empíricos, um no Brasil, e outro na Argentina, de cooperativas que trabalham em prol de agricultores familiares, com base no auxílio mútuo, para "remover obstáculos" e contribuir para a melhoria das condições gerais de vida desses agricultores.

\section{Cooesperança: um outro cooperativismo é possível}

A Cooesperança, vinculada ao Projeto Esperança ${ }^{10}$, congrega e articula associações de agricultores familiares, viabilizando a comercialização direta de alimentos ao seu consumidor. Assim, propõe, de forma integrada ao projeto, que a economia solidária seja uma impulsora de desenvolvimento sustentável e solidário no território (ARQUIDIOCESE DE SANTA MARIA, 2012).

Entre principais segmentos envolvendo os agricultores familiares coordenados pelo Projeto Esperança/Cooesperança estão o cooperativismo, a economia solidária e a autogestão. E, também, a agricultura e a agroindústria familiar; as políticas públicas; as feiras em rede do comércio justo e consumo ético e solidário; a segurança alimentar nutricional sustentável; e a Agroecologia (ARQUIDIOCESE DE SANTA MARIA, 2012).

Inserida no contexto agroecológico, a produção de alimentos orgânicos tem angariado adeptos. Muitos agricultores familiares estão em fase de transição, ou seja, deixando de praticar a agricultura convencional - que utiliza intensamente máquinas e insumos químicos - e passando a produzir orgânicos. Outros já se encontram em um estágio mais avançado, inclusive com certificação orgânica obtida por Sistema Participativo de Garantia (SPG).

De acordo com o Cadastro Nacional de Produtores Orgânicos (CNPO) atualizado pelo Ministério da Agricultura, Pesca e Abastecimento (MAPA), em dezembro de 2014, existem nove produtores de orgânicos certificados no Conselho Regional

\footnotetext{
${ }^{10}$ O Projeto Esperança - criado em 15 de agosto de 1987, a partir da inspiração de Dom Ivo Lorscheiter, Bispo Diocesano de Santa Maria, baseada no estudo do livro "A pobreza, riqueza dos povos: a transformação pela solidariedade", de Albert Tévoèdjré (TÉVOÉDJRÉ, 2002) - é um dos setores do Banco da Esperança da Arquidiocese de Santa Maria, que cria e desenvolve Projetos Alternativos Comunitários (PACs) com autogestão, cooperativismo e sustentabilidade, como um novo jeito de construir o desenvolvimento solidário e sustentável e encontrar soluções para os grandes problemas sociais, entre eles o desemprego, o êxodo rural, a fome, a miséria e a exclusão social no campo e na cidade (ARQUIDIOCESE DE SANTA MARIA, 2012, p. 8-9).
} 
de Desenvolvimento (COREDE Central ${ }^{11}$ ). Destes, oito pertencem à Cooesperança, demonstrando sua importância no cenário regional de produção de alimentos orgânicos.

Importante salientar que esse avanço foi possível graças a diversos fatores, dentre os quais podem ser citados o incentivo da cooperativa à produção orgânica de alimentos; as políticas públicas que permitem a certificação, por intermédio do SPG, e a venda direta ao consumidor, sem certificação, desde que os agricultores familiares integrem alguma Organização de Controle Social (OCS) cadastrada nos órgãos fiscalizadores. E, ainda, o aumento da demanda pelos consumidores e a afirmação do Feirão Colonial ${ }^{12}$ como ponto de comercialização.

No Feirão Colonial da Cooesperança, de acordo com os depoimentos dos agricultores familiares entrevistados, verifica-se um contínuo crescimento da procura por alimentos orgânicos. Isto justifica o aumento da produção, principalmente de hortifrúti nas unidades produtivas, e a ampliação do espaço destinado à comercialização a fim de disponibilizar maior oferta de alimentos ao consumidor.

Esse movimento transformador da realidade desses agricultores foi e continua sendo possível por meio de um esforço solidário dos agricultores familiares da Cooesperança. Estes passaram a ampliar a produção, melhorar a qualidade dos alimentos e ofertar maior variedade de produtos para atrair o consumidor e fazer frente à demanda cada vez maior por alimentos orgânicos.

Para compreender a evolução desse processo, conhecer a realidade a respeito do fortalecimento desses agricultores, a sua inclusão social e consequente sobrevivência no mercado, destacam-se dois depoimentos.

No primeiro depoimento, o agricultor familiar " $A$ " expõe detalhes sobre a evolução do Feirão Colonial e o êxito do Projeto Esperança.

Observa-se que a cooperação entre os integrantes da Cooesperança aparece como esteio de um projeto que prospera e proporciona aos agricultores familiares uma melhor qualidade de vida, com melhoria das condições socioeconômicas, ambientais e culturais:

$\overline{11}$ O COREDE Central foi criado em 16 de junho de 1991, com objetivos de estimular a sociedade a participar das discussões sobre o planejamento do desenvolvimento regional, exercer um papel de entidade representativa e contribuir para o desenvolvimento da economia dos municípios que o compõem. Esse Conselho é composto, atualmente, por dezenove municípios: Agudo, Dilermando de Aguiar, Dona Francisca, Faxinal do Soturno, Formigueiro, Itaara, Ivorá, Jari, Júlio de Castilhos, Nova Palma, Pinhal Grande, Quevedos, Santa Maria (cidade polo da região), São João do Polêsine, São Martinho da Serra, São Pedro do Sul, Silveira Martins, Toropi e Tupanciretã.

12 O Feirão Colonial é uma das atividades do Projeto Esperança/Cooesperança, setor vinculado ao Banco da Esperança da Arquidiocese de Santa Maria. Foi criado em 10 de abril de 1992, com a participação efetiva e comprometida dos produtores rurais e urbanos associados ao Projeto e de consumidores conscientes da importância de consumir um alimento saudável, organizados na Região Central-RS. No Feirão, a comercialização se dá de forma direta entre o produtor organizado e o consumidor (ARQUIDIOCESE DE SANTA MARIA, 2012, p. 42). 
Às vezes, nem dá para acreditar que começamos expondo nossos produtos em barracas, nesse mesmo local, em 1993. [...] Não tinha tempo ruim, no calor ou no frio, vendíamos nossas frutas e verduras para sobreviver e sustentar a família, [...] não era fácil e, quando chovia, era um horror, um barro só. Hoje, a gente vê esses pavilhões bonitos, os acessos asfaltados, muita gente comprando, todo esse movimento, e fica feliz de ver que o trabalho do nosso bispo Dom Ivo e, posteriormente, da irmã Lurdes valeu a pena, que o Projeto Esperança deslanchou, que a Cooesperança é uma realidade. A cooperação de todos, nas atividades, congrega o grupo. E a união de todos faz a força. Nós somos parte dessa história, e ela mudou nossa vida para melhor (RELATO DO ENTREVISTADO "A", grifo nosso).

No depoimento do agricultor familiar "B", percebe-se a influência da cooperativa, no sentido de dar suporte à agricultura familiar, não só servindo de apoio à comercialização, mas também debatendo, alertando, orientando, etc. sobre o impacto e as possibilidades que as políticas públicas voltadas à agricultura familiar podem proporcionar.

Quando surgiu a Lei [Lei 11.947/2009 e a Resolução CD/FNDE 26/2013], que possibilitou o fornecimento de alimentos para escolas públicas, a Cooesperança incentivou todos agricultores para que estudassem a lei para que tivessem condições de fornecer os alimentos para as escolas. Essa oportunidade [política pública] foi uma criação excelente para incentivar a agricultura familiar nos municípios, porque você produz para a própria comunidade, [...] apesar de que, às vezes, demora para receber [o pagamento], mas é certo que recebe, e isso é importante. Outra coisa boa é que você pode programar seu plantio, porque sabe o que precisa produzir para atender ao que foi licitado. [...] Mas, a responsabilidade também é grande por causa do compromisso que temos com as escolas. Não é só uma questão de vender o produto, é uma questão de fornecer um alimento saudável. [...] Minha filha estuda numa escola que eu forneço legumes e verduras, e eu quero que ela e todas as crianças tenham as melhores hortaliças para a merenda; e é bom também porque as crianças lá da escola da minha filha aprendem desde cedo o que é um produto saudável, orgânico e os benefícios de plantar e consumir esses alimentos (RELATO DO ENTREVISTADO " $B$ ", grifos nossos).

Verifica-se que essa política viabilizou mais uma forma de comercialização de alimentos oriundos da agricultura familiar. Essa comercialização possibilitou a ampliação da renda da família e impulsionou a categoria agricultor familiar ao desempenho de uma função transformadora dos valores culturais ao influenciar no aprendizado das crianças. Portanto, sustenta-se a ideia de que a organização em rede é essencial para que o agricultor familiar tenha capacidade de competir no mercado. Nesse contexto, a Teia Esperança ${ }^{13}$, gerada na Cooesperança, apresenta-se como uma alternativa sustentável, capaz de inserir os agricultores fami-

$\overline{13}$ A Teia Esperança, criada em 14 de janeiro de 2003, é a rede de empreendimentos solidários associados ao Projeto Esperança/Cooesperança cujo objetivo principal é articular esses empreendimentos solidários, para um maior escoamento da produção, e proporcionar mais qualidade nos pontos de comercialização direta em vários municípios do COREDE Central (ARQUIDIOCESE DE SANTA MARIA, 2012, p. 40). 
liares em diversos pontos de comercialização com a "[...] perspectiva de gerar trabalho e renda, dignidade pelo trabalho organizado, com valorização do trabalho acima do capital, na construção da cidadania e inclusão social" (ARQUIDIOCESE DE SANTA MARIA, 2012, p. 40).

Diante do exposto, conclui-se que na inclusão social dos agricultores familiares vinculados à Cooesperança interferem as políticas públicas, os processos organizativos de produção e de comercialização de alimentos, as ações individuais (nas unidades de produção) e coletivas (formas de organização de ação coletiva, como o associativismo e o cooperativismo, por exemplo). E ainda, a capacidade demonstrada pela cooperativa de agregar, articular e aglutinar esses agricultores.

\title{
6 La Choza: cooperativismo a serviço da vida social
}

A La Choza vincula-se à Fundación La Choza ${ }^{14}$, desenvolvendo suas atividades agropecuárias de acordo com os preceitos do sistema biodinâmico de produção, buscando conscientizar as pessoas para a importância da alimentação saudável. Para isso, promove atividades educativas relacionadas à vida no campo e voltadas, principalmente, para crianças e adolescentes (FUNDACIÓN LA CHOZA, 2016b).

De acordo com Trivelatto e Freitas (2003), o sistema biodinâmico relaciona-se com a Antroposofia ${ }^{15}$ e foi criado por Rudolph Steiner, filósofo e matemático austríaco. Os requerimentos básicos desse sistema são:

\begin{abstract}
- a propriedade agrícola entendida como um organismo em que todas as suas partes: fauna, flora, solo, corpos d'água e ser humano, estão interligadas e são interdependentes;

- preocupação com a harmonia do ambiente, buscando o estabelecimento de um equilíbrio paisagístico e ecológico, por meio da plantação de árvores e arbustos em bordaduras e cercas vivias, recuperação de áreas degradadas utilizando a flora nativa;

- interação entre a produção vegetal e animal e aproveitamento dos resíduos de ambas as atividades na elaboração do composto, que deve ser produzido dentro da propriedade;

- influência cósmica sobre as plantas, a qual implica respeito ao calendário astrológico para realizar a semeadura e demais atividades agrícolas; $\mathrm{e}$ - uso de preparados biodinâmicos à base de extratos vegetais e de soluções orgânicas e minerais que, incorporados nas pilhas de compostagem, ou aplicados diretamente sobre o solo e as plantas, possuem efeito dinamizador sobre as forças naturais (TRIVELATTO; FREITAS, 2003, p. 11).
\end{abstract}

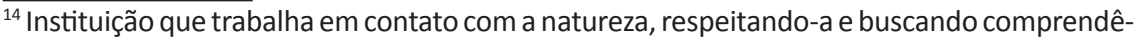
la. Tem o intuito de, através da agricultura e pecuária biológico-dinâmica, conscientizar as pessoas sobre a importância de adquirir o hábito de uma alimentação saudável. Deseja, também, que crianças e adolescentes possam envolver-se com a vida no campo por meio de diversas atividades educativas (FUNDACIÓN LA CHOZA, 2016b).

15 A Antroposofia, do grego "conhecimento do ser humano", introduzida no início do século XX pelo austríaco Rudolf Steiner, pode ser caracterizada como um método de conhecimento da natureza do ser humano e do universo, que amplia o conhecimento obtido pelo método científico convencional, bem como a sua aplicação em praticamente todas as áreas da vida humana (SAB, 2016).
} 
Seguindo esses preceitos, a La Choza organiza-se em uma unidade produtiva onde dezoito pessoas habitam e trabalham. A divisão para o trabalho ocorre da seguinte maneira: quatro atuam na horta e pomar, dez trabalham no tambo de leite, dois são os responsáveis pelo gerenciamento da propriedade (instalações, máquinas e equipamentos, etc.), e dois encarregam-se da comercialização dos alimentos produzidos. Essa estrutura e o sistema de cooperativa para produção e comercialização de alimentos biodinâmicos funcionam desde 2011, quando foi criada a La Choza. A articulação do grupo de agricultores familiares tem o intuito de ampliar (quantidade) e melhorar (qualidade) o desempenho das atividades produtivas, de desenvolver, solidariamente, ações relacionadas a questões tecnológicas, organizacionais, jurídicas, econômicas, entre outras, e de proporcionar melhores condições socioeconômicas para eles próprios e suas respectivas famílias.

O poder da La Choza, considerando os processos organizativos para a produção, caracteriza essa instituição como uma estrutura dinamizadora de efetiva inclusão social, porque congrega os cooperados no trabalho realizado na propriedade. E, nas atividades festivas e de lazer, a mesma integra-os com a comunidade externa, transmitindo saberes - como o relativo a alimentos saudáveis - e/ou simplesmente levando-os a interagir sobre o meio ambiente, etc.

As ações desenvolvidas pela La Choza, como visitas guiadas nos espaços de produção, cursos sobre agricultura biológico-dinâmica, acampamentos para crianças e adolescentes, cursos e atividades artísticas, etc., auxiliam na propaganda - marketing "boca a boca" - da qualidade dos alimentos produzidos. Assim, contribuem para que a cooperativa seja reconhecida como líder em produtos lácteos biodinâmicos e uma referência em agricultura ecológica na Argentina, particularmente em Buenos Aires - capital federal.

A partir da percepção dos agricultores familiares membros dessa cooperativa sobre a importância da cooperação, elegem-se dois depoimentos que propiciam a compreensão do empoderamento desses agricultores, no sentido de realizar ações que fizeram com que eles evoluíssem e se fortalecessem.

Com isso, garantem a sobrevivência própria e a de suas famílias, melhorando a qualidade de vida e incluindo-se e/ou ascendendo socialmente.

A agricultura mudou muito nos últimos anos. Mas, para nós que seguimos os princípios e fundamentos da Antroposofia, é fundamental aprender como cultivar os alimentos para nutrir adequadamente o ser humano na sua jornada evolutiva. [...] Nós somos unidos e colaboramos uns com os outros para que possamos produzir e vender os produtos. [...] Dentro dessa estrutura que criamos, nós realizamos cursos, para que as pessoas conheçam os princípios que nos guiam, e, a partir dessa ação concreta, podemos produzir uma mudança de pensamento nas pessoas. Não é só agricultura, mas o entendimento do todo, um novo entendimento sobre o meio ambiente, a economia, o meio em que vivemos e a sociedade [...](RELATO DO ENTREVISTADO "C", tradução nossa). 
Depois que criamos a cooperativa, nós conseguimos colocar os nossos produtos em grandes feiras de produtos orgânicos e naturais de Buenos Aires [capital federal] como Buenos Aires Market e El Galpón. [...] Temos um caminhão que utilizamos para transportar os alimentos até as feiras e para fazer entregas a domicílio dos produtos pedidos, diariamente, pela internet, por e-mail ou por telefone.

Verifica-se que o elo entre a possibilidade de avanços dessa cooperativa argentina e a necessidade dos agricultores familiares oportunizou a reação positiva desses trabalhadores para continuarem produzindo e vendendo alimentos, conforme relato do agricultor:

Depois que eu comecei a praticar a agricultura biodinâmica, minha vida e a de minha família mudou [para melhor]. [...] Hoje, me sinto feliz por produzir e compartilhar um alimento saudável com minha esposa e filha. Aprendi a conviver de forma amigável e racional com o ser humano, com os animais, as plantas e os minerais, porque entendi que tudo está interligado. [...] Aqui [na La Choza], em 2011, nos unimos e resolvemos criar a cooperativa para poder produzir e vender alimentos saudáveis. [...] Depois, com o tempo, surgiram grandes oportunidades para interagir e trabalhar a mudança de pensamento da sociedade, especialmente, quando as pessoas vêm visitar a propriedade onde a gente vive, conhecem o modo como trabalhamos e produzimos os alimentos que vendemos. [...] As pessoas passaram a divulgar o que viam aqui, a procura por nossos produtos aumentou e, com isso, os nossos ganhos aumentaram também. Assim, conseguimos melhorar nossas vidas (RELATO DO ENTREVISTADO “D”, tradução nossa).

No caso da La Choza Cooperativa, podemos constatar que a estrutura e a forma de gestão organizacional conduzem para uma série de relações de cooperação social entre os agricultores familiares. A consequência mais expressiva dessa interação é a inclusão social desses trabalhadores no território, a apresentação de um significativo grau de integração com a sociedade.

Nesse processo, infere-se que, quando os agricultores familiares integrados, articulados e organizados compartilham seus valores, criam formas de empoderamento que vão além da produção de alimentos biodinâmicos, passando a transformar a sociedade.

\section{Considerações finais}

O objetivo do trabalho, considerando a evolução histórica e doutrinária do cooperativismo, foi descrever os processos organizativos de cooperação desenvolvidos nas cooperativas Cooesperança (Brasil) e La Choza (Argentina). A partir do contexto histórico-doutrinário do cooperativismo e do processo de cooperação existente entre os agricultores familiares, procura-se identificar os desafios para a construção da sustentabilidade no desenvolvimento territorial. E, ao especificar os dois casos, visualiza-se a transformação que está acontecendo e as possibilidades de mudança nos territórios rurais por meio da cooperação para a 
produção e para a comercialização dos alimentos orgânicos e biodinâmicos.

A Cooesperança, por meio do Feirão Colonial e da Teia Esperança, contribui deveras, viabilizando a comercialização dos alimentos orgânicos produzidos pelos agricultores familiares em suas unidades produtivas, além de proporcionar a integração entre eles e os consumidores. A La Choza, por sua vez, destaca-se pela estrutura e organização que possibilitam desenvolver de forma independente, isto é, com autonomia, todos os segmentos (excluídos a certificação, o processamento secundário e a exportação) da cadeia produtiva, desde o plantio até a venda dos produtos.

Ambas as experiências revelam que, por meio dos valores e princípios cooperativos, produzem-se efeitos positivos em relação ao desenvolvimento individual e coletivo dos agricultores familiares, valorizando o trabalho, promovendo a inclusão social e melhorando a qualidade de vida. Essas cooperativas, em seu dia a dia, evidenciam valores cooperativos, tais como responsabilidade, democracia, igualdade e solidariedade. Ademais, observa-se que os princípios de Rochdale - ratificados pela $\mathrm{ACl}$, em 1995 - mantêm-se como pilares na organização e no desenvolvimento de suas atividades.

Após a realização do estudo, constatou-se que as ações desenvolvidas por essas cooperativas estão ancoradas nas virtudes e nos objetivos cultuados pela doutrina do cooperativismo. Entre estes, destacam-se a democracia, o trabalho em grupo, a participação ampla dos agricultores nas atividades relacionadas à cidadania e à autogestão, gerando conquistas pessoais e coletivas, por meio de ações solidárias que impulsionam a melhoria da qualidade de vida e a inclusão social.

Por fim, entendem que o cooperativismo se projeta por meio de processos organizativos que consistem em articulações e organizações que acontecem no território e que, com o passar do tempo, transformam-se ou (re)criam outros novos processos organizativos. Isso ocorre porque há uma constante interação entre indivíduos/atores sociais, os quais interferem nas dimensões sociais, econômicas, políticas, culturais e ambientais.

\section{Referências}

ARQUIDIOCESE DE SANTA MARIA. Projeto Esperança/Cooesperança: uma experiência aprendente e ensinante. 25 anos construíndo cooperação, economia solidária e cidadania. Santa Maria: Pallotti, 2012.

BASUALDO, E. Sistema político y modelo de acumulación: tres ensayos sobre la Argentina actual. Buenos Aires: Atuel, 2011.

BÜTTENBENDER, Pedro Luiz. Doutrina e educação cooperativa. Ijuí: Unijuí, 2008.

CARRICART, P. Cooperativas rurales y territorios en la Región Pampeana Argentina: transformaciones sociales, económicas y organizacionales. Buenos Aires: La Colmena, 2012.

CENZI, N. L. Cooperativismo: desde as origens ao projeto de lei de reforma do sistema cooperativo brasileiro. Curitiba: Juruá, 2012. 
COOPERATIVAS DE LAS AMÉRICAS. Princípios y valores cooperativos. Disponível em: <http://www.aciamericas.coop/Principios-y-Valores-Cooperativos-4456>. Acesso em: 30 jan. 2017.

- ¿Qué es la Alianza Cooperativa Internacional? Disponível em:

<http://www.aciamericas.coop/Que-es-la-Alianza-Cooperativa-Internacional>. Acesso em: 2 nov. 2016.

. ¿Quiénes somos? Disponível em: <http://www.aciamericas.coop/ Quienes-somos-2092>. Acesso em: 2 nov. 2016.

DEVOTO, F. J.; BORIS, F. Brasil e Argentina: um ensaio de história comparada. São Paulo: Editora 34, 2004.

FUNDACIÓN LA CHOZA. Actividades. Disponível em: <http://fundacionlachoza. org.ar/actividades.php>. Acesso em: 28 out. 2016a.

. Actividades agropecuarias al servicio de la vida social. Disponível em:

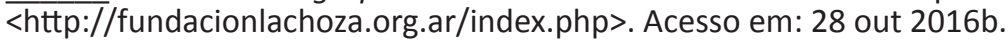

GERHARDT, T. H. et al. Estrutura do projeto de pesquisa. In: GERHARDT, T. H.; SILVEIRA, D. T. (Orgs.). Métodos de pesquisa. Porto Alegre: UFRGS, 2009. p. 65-88.

GIL, A. C. Como elaborar projetos de pesquisa. 4. ed. São Paulo: Atlas, 2008.

GOHN, M. da G. Abordagens teóricas no estudo dos movimentos sociais na América Latina. Caderno CRH, Salvador, v. 21, n. 54, p. 439-455, set./dez. 2008. Disponível em: <http://www.scielo.br/pdf/ccrh/v21n54/03.pdf>. Acesso em: 3 set. 2016.

LUDKE, M.; ANDRÉ, M. E. D. A. Pesquisa em educação: abordagens qualitativas. São Paulo: EPU, 1986.

OBSCHATKO, E. S. de; BASAÑES C. C.; MARTINI G. D. Las cooperativas agropecuarias en la República Argentina: diagnóstico y propuestas. Buenos Aires: Ministerio de Agricultura, Ganadería y Pesca de la Nación/IICA Argentina, 2011.

PINHO, D. B. A doutrina cooperativa nos regimes capitalista e socialista: suas modificações e sua utilidade. 2. ed. São Paulo: Pioneira, 1966a.

. Economia e cooperativismo. São Paulo: Saraiva, 1977. . Que é cooperativismo. São Paulo: São Paulo, 1966b.

RECH, D. Cooperativas: uma alternativa de organização popular. Rio de Janeiro: DP\&A, 2000.

SAB. Sociedade Antroposófica no Brasil. Antroposofia. Disponível em: <http://www.sab.org.br/portal/antroposofia2>. Acesso em: 28 out. 2016.

SINGER, P. A economia solidária no governo federal. Mercado de trabalho: conjuntura e análise. Rio de Janeiro: IPEA, n. 24, p. 3-5, ago. 2004. Disponível em: <http://www.ipea.gov.br/portal/images/stories/PDFs/mercadodetrabalho/ mt_24c.pdf>. Acesso em: 12 set. 2016. 
TRIVELATTO, M. D.; FREITAS, G. B. de. Panorama da agricultura orgânica. In: STRINGHETA, P. C.; MUNIZ, J. N. (Eds.). Alimentos orgânicos: produção, tecnologia e certificação. Viçosa: UFV, 2003. p. 9-35.

TÉVOÉDJRÉ, A. A Pobreza, riqueza dos povos: a transformação pela solidariedade. Petrópolis: Vozes, 2002.

VILCHEZ, J. O. Antologia 'doctrina cooperativa'. San José: EUNED, 1986. 